\title{
Application of GDAHP on Quality Evaluation of Urban Lake Landscape
}

\author{
Lifang QIAO, Yichuan ZHANG \\ School of Landscape Architecture, Henan Institute of Science and Technology Xinxiang, \\ Henan, China \\ E-mail: zhangyichuan2002@163.com,qiaolifang2002@163.com \\ Received September 14, 2009; revised October 8, 2009; accepted November 4, 2009
}

\begin{abstract}
The quality evaluation of urban lake landscape (QEULL) is extremely important for the healthy development of lake landscape. In this research, the evaluation model was established with the group decision analytic hierarchy process (GDAHP) method, which consisted of four layers including the target layer, the factor layer, the index layer and the criterion layer, thus forming a model tree based on their subordinate relationships. The GDAHP method was employed to determine the weights of constituting factors of each layer in the evaluation model, and the fuzzy method was used to establish the factors remark sets of the criterion layer, thus the single-layer evaluation and comprehensive evaluation of urban lake landscape quality was carried out. Quality evaluation model of urban lake landscape established based on the GDAHP method can provide grounds for planning, design, and renewal of urban lake landscape. This model has been used to evaluate and analyze the artificial lake in People's Park of Xinxiang City, Henan Province. The results proved that the overall landscape quality of the artificial lake of Peoples Park in Xinxiang city was good.
\end{abstract}

Keywords: Quality Evaluationl, Urban Lake Landscape, GDAHP

\section{Introduction}

The urban lake is an important type of wetland, playing a crucial role in maintaining eco-balance, protecting biodiversity, preserving fresh water resources, regulating and storing flood waters, adjusting the climate, replenishing underground water, degrading pollutants, and providing important resources for our life, production and social development [1]. In addition, it also has social functions including relaxation [2], entertainment and economic ones such as tourism development [3]. Modern urban residents show a keen interest in water landscapes, especially lakes [4]. In order to satisfy such needs, a large number of lakes have been constructed in many cities. In spite of the achievements, there have existed many problems in lake landscape construction $[5,6]$, in some, eco-protection was overemphasized while the public needs of traveling and relaxation were ignored; in others, the development was totally centered on relaxation and entertainment while the construction requests of the ecological environment have been neglected. Such problems have seriously undermined the healthy development of lake landscapes. Therefore, how to accurately evaluate the quality of lake landscape to provide grounds for planning and design as well as renewal and construc- tion of such landscape has become a project deserving research. Zhang Fengling and others thereby have established the appraisal standards for urban river and lake ecological health [7].

The quantitative methods have the features of accuracy and easy for comparison, therefore it will be a wide prospect applying it in the QEULL.

The AHP was first introduced by Saaty in 1971 to solve the scarce resources allocation and planning needs for the military [8]. Since its introduction, the AHP has become one of the most widely used multiple-criteria decision-making methods, and has already been applied in many field such as political, economic, social, management sciences, industrial controlling, engineering, medicine and mining industry etc.

For some complicated decision problems, in order to avoid the mistakes and to improve the accuracy, it is needed to rely on the wisdom of a group of experts to make a decision.

\section{Methods}

In this research, a model was established with the GDAHP method. Details steps are as follows.

Step 1: To establish the pairwise matrix $A$ : 


$$
A=\left[\begin{array}{ccc}
a_{11} & \ldots & a_{1 n} \\
\ldots & & \ldots \\
a_{n 1} & \ldots & a_{n n}
\end{array}\right]=\left[\begin{array}{ccc}
w_{1} / w_{1} & \ldots & w_{1} / w_{n} \\
\ldots & & \ldots \\
w_{n} / w_{1} & \ldots & w_{n} / w_{n}
\end{array}\right]
$$

where $w_{i}$ is the relative importance of the $i$ th index of the index layer, as shown in Table 1.

Step 2: To calculate the product of each line $M_{i}$ :

$$
M_{i}=\prod_{j=1}^{n} a_{i j} \quad(i=1,2, \ldots, n)
$$

Step 3: To calculate the $n$th roots $\left(\bar{W}_{i}\right)$ of $M_{i}$ :

$$
\overline{W_{i}}=\sqrt[n]{M_{i}} \quad(i=1,2, \ldots, n)
$$

Step 4: To obtain the weight of the $i$ th evaluation index $\left(W_{i}\right)$ by standardizing the $\bar{W}_{i}$ :

$$
W_{i}=\frac{\overline{W_{i}}}{\sum_{i=1}^{n} \overline{W_{i}}}
$$

Step 5: Consistency check:

The maximum eigen value $\lambda_{\max }$ is:

$$
\lambda_{\max }=\frac{1}{n} \sum_{i=1}^{n} \frac{\left(A W_{i}\right)}{W_{i}}=\frac{1}{n} \sum_{i=1}^{n} \frac{\sum_{j=1}^{n} a_{i j} W_{i}}{W_{i}}
$$

The consistency index $(C I)$ is:

$$
C I=\frac{\lambda_{\max }-n}{n}
$$

The consistency ratio $(C R)$ is:

$$
C R=\frac{C I}{R I}
$$

where $R I$ is the random index (Table 2). If $C R<0.1$, it means that evaluations tend to be consistent. For multiple levels, $C R H<0.1$ should be satisfied, and

$$
C R H=\frac{C I H}{R I H}
$$

where $C I H$ is the consistency index of the hierarchy, $R I H$ is the random index of the hierarchy, and $C R H$ is the consistency ratio of the hierarchy.

According to Step1 to Step 4, the local weights (LW) of each layer and the global weights (GW) are obtained, and the consistency check is tenable based on Step 5.

Step 6: Synthesize the fuzzy comprehensive evaluation result-vector $B$. Synthesize $A$ and $R$ of each evaluated object with the appropriate operator, and obtain the fuzzy comprehensive evaluation result-vector of each evaluated object:

$$
B=A \circ R=\left(b_{1}, b_{2}, \ldots, b_{\mathrm{m}}\right)
$$

Step 7: Calculate the value $S$, determine the quality
Table 1. The relative importance scales of AHP.

\begin{tabular}{cc}
\hline Relative importance & Scaled value \\
\hline Extremely important & 9 \\
Especially important & 7 \\
Obviously important & 5 \\
Fairly important & 3 \\
Equally important & 1 \\
Fairly not important & $1 / 3$ \\
Not important & $1 / 5$ \\
Less important & $1 / 7$ \\
Minimally important & $1 / 9$ \\
\hline
\end{tabular}

Table 2. Values of random consistency index RI.

\begin{tabular}{cccccc}
\hline Rank & 1 & 2 & 3 & 4 & 5 \\
R. I. & 0 & 0 & 0.52 & 0.89 & 1.12 \\
Rank & 6 & 7 & 8 & 9 & 10 \\
R. I. & 1.26 & 1.36 & 1.41 & 1.46 & 1.49 \\
\hline
\end{tabular}

ratings of lake landscape, and thus conduct its analysis.

$$
S=B \text {. Med. } V \mathrm{t}
$$

\section{Establish the Evaluation Model-With the Artificial Lake of People's Park in Xinxiang City}

\subsection{Establish the Evaluation Factor Set}

There are many factors influencing the QEULL. The indices which can reflect essentially the sustainable development of urban lake landscape should be selected and the tree of the QEULL was established (Table 3).

$U=\left\{U_{1}, U_{2}, U_{3}, U_{4}\right\}=\{$ nature, ecology, landscape, traffic $\} ; U_{1}=\left\{U_{11}, U_{12}\right\}=\{$ waterfront, vegetation $\} ; U_{2}=\left\{U_{21}\right.$, $\left.U_{22}\right\}=\{$ aquatic ecology, terrestrial ecology $\} ; U_{3}=\left\{U_{31}\right.$, $\left.U_{32}\right\}=\{$ function of use, psychological function $\} ; U_{4}=$ $\left\{U_{41}, U_{42}\right\}=\{$ internal traffic, enternal traffic $\} ; U_{11}=\left\{U_{111}\right.$, $\left.U_{112}\right\}=\{$ shoreline, embankment $\} ; U_{12}=\left\{U_{121}, U_{122}\right\}=$ \{community; species $\} ; U_{21}=\left\{U_{211}, U_{212}, U_{213}\right\}=\{$ water content, water quality, aquatic biology $\} ; U_{22}=\left\{U_{221}, U_{222}\right\}$ $=\{$ width of vegetation zone, coverage of vegetation zone $\} ; \quad U_{31}=\left\{U_{311}, U_{312}, \quad U_{313}, U_{314}, U_{315}, U_{316}\right\}=\{$ space, facilities, illumination, hydrophilicity, safety, activities $\}$; $U_{32}=\left\{U_{321}, U_{322}\right\}=$ sense of beauty, culture $\} ; U_{41}=$ $\left\{U_{411}, U_{412}\right\}=\{$ accessibility, public traffic $\} ; U_{42}=\left\{U_{421}\right.$, $\left.U_{422}\right\}=\{$ connection, comfort level $\}$.

\subsection{Establish the Fuzzy Remark Set}

Establish the fuzzy remark set $V=\left\{v_{1}, v_{2}, v_{3}, v_{4}\right.$, $\left.v_{5}\right\}=\{$ Excellent, Good, Mediocre, Bad, Very bad $\}$, and 
respectively assign the value $V_{\mathrm{t}}=\left\{80<v_{1 \mathrm{t}} \leq 100,60<v_{2 \mathrm{t}} \leq 80\right.$, $\left.40<v_{3 \mathrm{t}} \leq 60,20<v_{4 \mathrm{t}} \leq 40,0<v_{5 \mathrm{t}} \leq 20\right\}$, Med. $v_{\mathrm{t}}=\{90,70,50$, $30,10\}$. Evaluation standards of criterion layer see Table 4 .

\subsection{Questionnaire}

10 sheets of questionnaire were handed out to the experts of landscape planning from Henan Agriculture University, Henan Institute of Science \& Technology and Zhengzhou University, etc, to determine the relative importance of each criterion. These experts between 40-60 years old have rich experience because they were engaged in the teaching, research and practice about lake landscape planning and design for a long time, all of them have managed the large-scale lake landscape planning and design directly.

\subsection{Weight and the Expert Evaluation}

The artificial lake of the People's Park in Xinxiang City has an area of 7.3 hectares, accounting for $15 \%$ of the whole area of the park, and playing the important roles of purifying water quality, regulating partial climate and providing entertainment and sightseeing, etc.

The weights of indices of each layer and the expert ratings are shown in Table 5.

\section{Evaluation Results}

\subsection{Single Evaluation Results}

The results (Table 6) were obtained in accordance with
Table 3. Tree of the QEULL.

\begin{tabular}{cccc}
\hline $\mathrm{U}$ & $\mathrm{U}_{\mathrm{i}}$ & $\mathrm{U}_{\mathrm{ij}}$ & $\mathrm{U}_{\mathrm{ijk}}$ \\
\hline & & Waterfront & Shoreline(SH) \\
& Nature & (W) & Embankment(EM) \\
& $(\mathrm{N})$ & Vegetation & Community(CO) \\
& & (V) & Species(SP) \\
& & Aquatic & Water content(WC) \\
& & ecology & Water quality(WQ) \\
& Ecology & (AE) & Aquatic biology(AB) \\
& (E) & Terrestrial & Width of vegetation zone(WVZ) \\
Lands & & ecology(TE) & Coverage of vegetation \\
cape & & & zone(CVZ) \\
qualit & & & Space(SPA) \\
y(LQ) & & Function of use & Facilities(FA) \\
& Landscape & Illumination(IL) & Hydrophilicity(HY) \\
& (L) & & Safety(HY) \\
& & & Activities(AC) \\
& & Psychological & Sense of beauty(SB) \\
& & function(PF) & Culture(CU) \\
& & Internal traffic & Accessibility(AC) \\
& Traffic & (IT) & Public traffic(PT) \\
& (T) & Eexternal traffic & Connection(CON) \\
& & (ET) & Comfort level(COM) \\
\hline
\end{tabular}

the step 4 and step 5. A computational process illustrates as follows:

$$
\begin{aligned}
& B_{11}=\left(\begin{array}{ll}
0.225 & 0.775
\end{array}\right) \circ\left\{\begin{array}{ccccc}
0.3 & 0.2 & 0.4 & 0.1 & 0 \\
0.5 & 0.3 & 0.2 & 0 & 0
\end{array}\right\} \\
& =\left(\begin{array}{lllll}
0.455 & 0.2775 & 0.245 & 0.0225 & 0
\end{array}\right) \\
& S\left(B_{11}\right)=90 \times 0.455+70 \times 0.2775+50 \times 0.245+30 \times 0.0225 \\
& +10 \times 0=73.3 \\
& B_{12}=\left(\begin{array}{ll}
0.829 & 0.171
\end{array}\right) \circ\left\{\begin{array}{ccccc}
0.3 & 0.4 & 0.1 & 0.2 & 0 \\
0.2 & 0.3 & 0.3 & 0.2 & 0
\end{array}\right\} \\
& =\left(\begin{array}{lllll}
0.2829 & 0.3829 & 0.1342 & 0.2 & 0
\end{array}\right)
\end{aligned}
$$

Table 4. Evaluation standards of criterion layer.

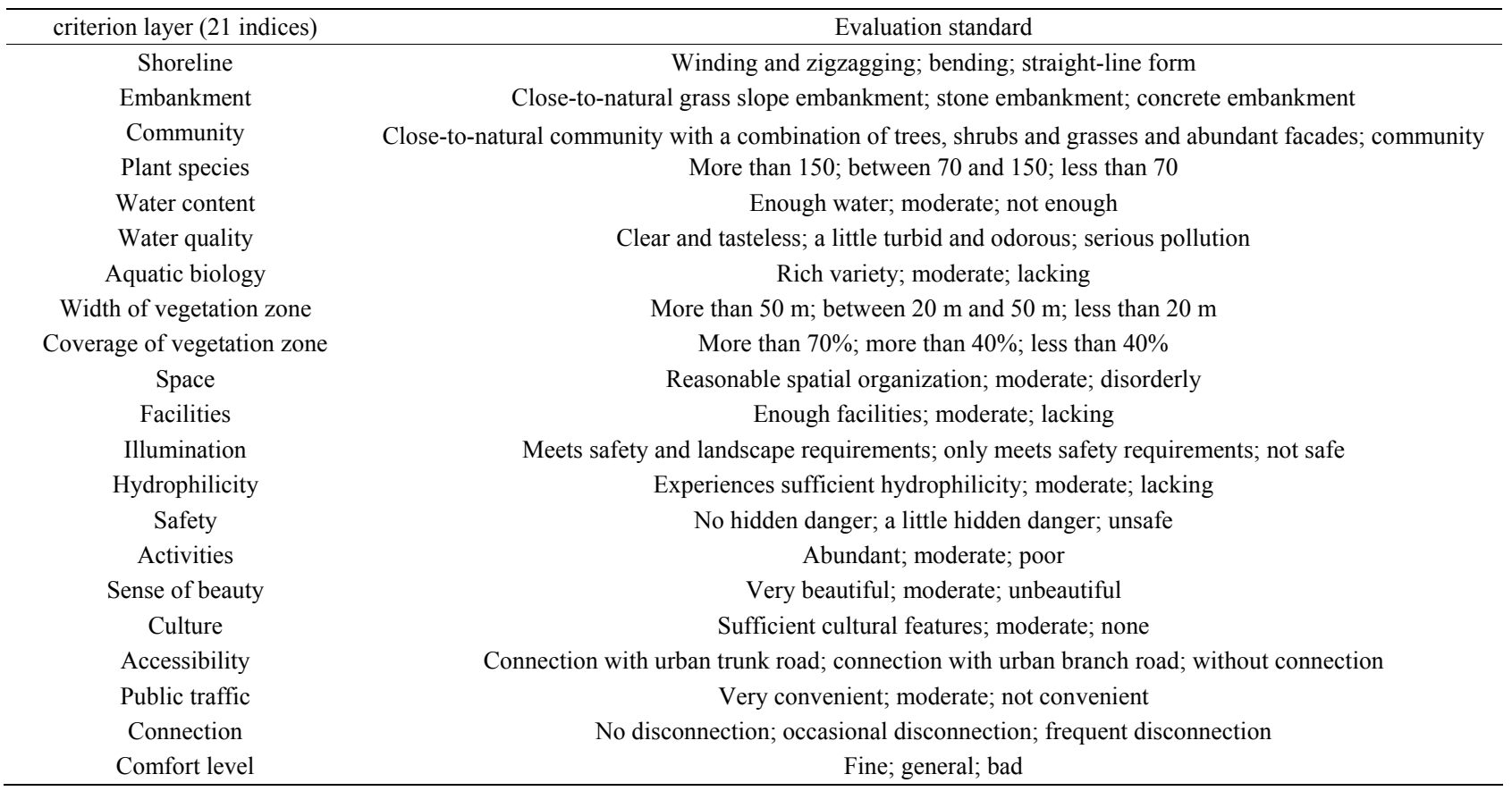


Table 5. Comprehensive evaluation results and Specialist comments.

\begin{tabular}{|c|c|c|c|c|c|c|c|c|c|c|c|c|}
\hline \multicolumn{8}{|c|}{ Comprehensive evaluation results } & \multicolumn{5}{|c|}{ Specialist comments } \\
\hline $\mathrm{U}$ & $\mathrm{U}_{\mathrm{i}}$ & LW & $\mathrm{U}_{\mathrm{ij}}$ & LW & $\mathrm{U}_{\mathrm{ijk}}$ & LW & GW & $\mathrm{v}_{1}$ & $\mathrm{v}_{2}$ & $\mathrm{v}_{3}$ & $\mathrm{v}_{4}$ & $\mathrm{v}_{5}$ \\
\hline & \multirow{4}{*}{$\mathrm{N}$} & \multirow{4}{*}{0.332} & \multirow{2}{*}{ W } & \multirow{2}{*}{0.163} & $\mathrm{SH}$ & 0.225 & 0.0121 & $3 / 10$ & $2 / 10$ & $4 / 10$ & $1 / 10$ & $0 / 10$ \\
\hline & & & & & EM & 0.775 & 0.0419 & $5 / 10$ & $3 / 10$ & $2 / 10$ & $0 / 10$ & $0 / 10$ \\
\hline & & & \multirow{2}{*}{$\mathrm{V}$} & \multirow{2}{*}{0.838} & $\mathrm{CO}$ & 0.829 & 0.2372 & $3 / 10$ & $4 / 10$ & $1 / 10$ & $2 / 10$ & $0 / 10$ \\
\hline & & & & & SP & 0.171 & 0.0484 & $2 / 10$ & $3 / 10$ & $3 / 10$ & $2 / 10$ & $0 / 10$ \\
\hline & \multirow{5}{*}{ E } & \multirow{5}{*}{0.432} & \multirow{3}{*}{$\mathrm{AE}$} & \multirow{3}{*}{0.866} & WC & 0.237 & 0.0883 & $7 / 10$ & $2 / 10$ & $1 / 10$ & $0 / 10$ & $0 / 10$ \\
\hline & & & & & WQ & 0.683 & 0.2586 & $9 / 10$ & $1 / 10$ & $0 / 10$ & $0 / 10$ & $0 / 10$ \\
\hline & & & & & $\mathrm{AB}$ & 0.080 & 0.0302 & $4 / 10$ & $2 / 10$ & $3 / 10$ & $0 / 10$ & $1 / 10$ \\
\hline & & & \multirow{2}{*}{$\mathrm{TE}$} & \multirow{2}{*}{0.134} & WVZ & 0.183 & 0.0107 & $1 / 10$ & $2 / 10$ & $5 / 10$ & $2 / 10$ & $0 / 10$ \\
\hline & & & & & $\mathrm{CVZ}$ & 0.817 & 0.0477 & $2 / 10$ & $2 / 10$ & $4 / 10$ & $1 / 10$ & $1 / 10$ \\
\hline & \multirow{8}{*}{$\mathrm{L}$} & \multirow{8}{*}{0.179} & \multirow{6}{*}{$\mathrm{FU}$} & \multirow{6}{*}{0.854} & SPA & 0.099 & 0.0143 & $7 / 10$ & $2 / 10$ & $0 / 10$ & $1 / 10$ & $0 / 10$ \\
\hline & & & & & FA & 0.356 & 0.0513 & $2 / 10$ & $4 / 10$ & $1 / 10$ & $3 / 10$ & $0 / 10$ \\
\hline & & & & & IL & 0.032 & 0.0046 & $6 / 10$ & $2 / 10$ & $1 / 10$ & $1 / 10$ & $0 / 10$ \\
\hline & & & & & HY & 0.138 & 0.0199 & $6 / 10$ & $4 / 10$ & $0 / 10$ & $0 / 10$ & $0 / 10$ \\
\hline & & & & & SA & 0.072 & 0.0104 & $4 / 10$ & $3 / 10$ & $1 / 10$ & $1 / 10$ & $1 / 10$ \\
\hline & & & & & $\mathrm{AC}$ & 0.303 & 0.0437 & $5 / 10$ & $1 / 10$ & $2 / 10$ & $2 / 10$ & $0 / 10$ \\
\hline & & & \multirow{2}{*}{$\mathrm{PF}$} & \multirow{2}{*}{0.146} & $\mathrm{SB}$ & 0.838 & 0.0204 & $3 / 10$ & $1 / 10$ & $6 / 10$ & $0 / 10$ & $0 / 10$ \\
\hline & & & & & $\mathrm{CU}$ & 0.163 & 0.0039 & $1 / 10$ & $7 / 10$ & $0 / 10$ & $1 / 10$ & $1 / 10$ \\
\hline & \multirow{4}{*}{$\mathrm{T}$} & \multirow{4}{*}{0.057} & \multirow{2}{*}{ IT } & \multirow{2}{*}{0.583} & $\mathrm{AC}$ & 0.775 & 0.0256 & $2 / 10$ & $5 / 10$ & $1 / 10$ & $1 / 10$ & $1 / 10$ \\
\hline & & & & & $\mathrm{PT}$ & 0.225 & 0.0074 & $5 / 10$ & $4 / 10$ & $0 / 10$ & $1 / 10$ & $0 / 10$ \\
\hline & & & \multirow{2}{*}{ ET } & \multirow{2}{*}{0.417} & $\mathrm{CON}$ & 0.817 & 0.0191 & $6 / 10$ & $1 / 10$ & $3 / 10$ & $0 / 10$ & $0 / 10$ \\
\hline & & & & & $\mathrm{COM}$ & 0.183 & 0.0043 & $3 / 10$ & $4 / 10$ & $2 / 10$ & $1 / 10$ & $0 / 10$ \\
\hline
\end{tabular}

$$
\begin{aligned}
& S\left(B_{12}\right)=90 \times 0.2829+70 \times 0.3829+50 \times 0.1342^{\prime}+30 \times 0.2 \\
& +10 \times 0=65 \\
& B_{1}=\left(\begin{array}{ll}
0.163 & 0.838
\end{array}\right) \circ\left\{\begin{array}{lllll}
0.455 & 0.2775 & 0.245 & 0.0225 & 0 \\
0.2829 & 0.3829 & 0.1342 & 0.2 & 0
\end{array}\right\} \\
& =\left(\begin{array}{lllll}
0.3112 & 0.3661 & 0.1524 & 0.1713 & 0
\end{array}\right) \\
& S\left(B_{1}\right)=90 \times 0.3112+70 \times 0.3661+50 \times 0.1524+30 \times 0.1713 \\
& +10 \times 0=66.4
\end{aligned}
$$

It can be concluded from the above single evaluation results (Table 6) that among the landscape quality of the artificial lake of People's Park in Xinxiang, the ecologi-

\begin{tabular}{|c|c|c|c|}
\hline $\mathrm{B}_{\mathrm{i}}$ & $\mathrm{S}$ & $\mathrm{B}_{\mathrm{ij}}$ & $\mathrm{S}$ \\
\hline $\begin{array}{c}0.3112,0.3661,0.1524 \\
0.1713,0\end{array}$ & 66.4 & $\begin{array}{c}0.455,0.2775,0.245, \\
0.0225,0 \\
0.2829,0.3829,0.1342, \\
0.2,0\end{array}$ & 65.0 \\
\hline $\begin{array}{c}0.7281,0.1409,0.0974 \\
0.0159,0.0179\end{array}$ & 80.9 & $\begin{array}{c}0.8126,0.1317,0.0477 \\
0,0.008 \\
0.1817,0.2,0.4183 \\
0.1183,0.0817\end{array}$ & 55.6 \\
\hline $\begin{array}{c}0.4002,0.2643,0.1644 \\
0.1635,0.0085\end{array}$ & 67.7 & $\begin{array}{c}0.4228,0.2757,0.1066 \\
0.1887,0.0072 \\
0.2677,0.1979,0.5028 \\
0.0163,0.0163\end{array}$ & 68.4 \\
\hline $\begin{array}{c}0.3833,0.3430,0.1627 \\
0.0659,0.0452\end{array}$ & 69.1 & $\begin{array}{c}0.2675,0.4775,0.0775 \\
0.1,0.0775 \\
0.5451,0.1549,0.2817 \\
0.0183,0\end{array}$ & 65.2 \\
\hline
\end{tabular}
cal factor was excellent, and the ecological, landscape and communication factors were good.

\subsection{Comprehensive Evaluation Results}

$$
\begin{aligned}
& B_{U}=\left(\begin{array}{lllll}
0.332 & 0.432 & 0.179 & 0.057
\end{array}\right) \circ \\
& \left\{\begin{array}{lllll}
0.3112 & 0.3661 & 0.1524 & 0.1713 & 0 \\
0.7281 & 0.1409 & 0.0974 & 0.0159 & 0.0179 \\
0.4002 & 0.2643 & 0.1644 & 0.1635 & 0.0085 \\
0.3833 & 0.343 & 0.1627 & 0.0659 & 0.0452
\end{array}\right\} \\
& =\left(\begin{array}{lllll}
0.5113 & 0.2493 & 0.1314 & 0.0968 & 0.0118
\end{array}\right) \\
& S(u)=90 \times 0.5113+70 \times 0.2493+50 \times 0.1314+30 \times 0.0968 \\
& +10 \times 0.0118=73.1
\end{aligned}
$$

Table 6. Index weight value of modification.

The results proved that the overall landscape quality of the artificial lake of Peoples Park in Xinxiang city was good. 


\section{Conclusions}

1) In this research, the evaluation model is established with the GDAHP method, which consists of four layers including the target, the factor, the index and the criterion, thus forming a model tree based on their subordinate relationships. The GDAHP method is employed to determine the weights of constituting factors of each layer in the evaluation model, and the Fuzzy method to establish the remark sets of factors of the criterion layer, thus the single-layer evaluation and comprehensive evaluation of urban lake landscape quality is carried out.

2) Application of quantitative methods in the quality evaluation of urban lake landscape in this research has remedied the disadvantages of subjective evaluation, improving efficiency and accuracy. This model can be employed to compare the landscape quality of different lakes as well as for the optimal selection of different plans for the same lake landscape.

3) This model has been used to evaluate the landscape quality of a lake in Xinxiang city, Henan province and analyze the quality of indexes of each layer as well as the overall quality, thus providing grounds for landscape renewal and reconstruction.

\section{References}

[1] C. H. Feng, H. X. Liu, and J. M. Yu, "The water require- ment analysis of lake ecological system based on ecological service," Research of Soil and Water Conservation, Vol. 14, No. 3, pp. 161-165, 2007.

[2] L. Lu and X. L. Sun, "The development, problem and prospect of Chinese lake tourism," Journal of Anhui Normal University(Natural Science), Vol. 31, No. 4, pp. 391-394, 2008.

[3] R. Q. Jiang, “On sustainable development of the Qiandao Lake tourism via establishing a noted brand of lake leisure tourism," Economic Geography, pp. 98-101, 2006.

[4] P. Zhao and Y. Li, "The open space and civic leisure life: on the public attribute of West Lake in Hangzhou," Chinese Landscape Architecture, No. 1, pp. 46-49, 2008.

[5] X. F. Zhang, Z. W. Liu, Y. F. Xie, and G. R. Chen, "Evaluation on the changes of ecosystem service of urban lakes during the degradation process: a case study of Xiannü Lake in Zhaoqing, Guangdong Province," Acta Ecologica Sinica, Vol. 27, No. 6, pp. 2349-2354, 2007.

[6] Y. B. Liu, Q. F. Wang, and H. M. Chen, "The development, protecting and planning envision of lakes in Wuhan city," Economic Geography, Vol. 24, No. 2, pp. 192-196, 2004.

[7] F. L. Zhang, J. L. Liu and Z. F. Yang, "Ecosystem health assessment of urban rivers and lakes for six lakes in Beijing," Acta Ecologica Sinica, Vol. 25, No. 11, pp. 3019-3027, 2005.

[8] F. T. S. Chan and N. Kumar, "Global supplier development considering risk factors using fuzzy extended AHP-based approach," Omega Vol. 35, pp. 417-431, 2007. 